\title{
Optimizing the quadruple-potential waveform for the pulsed amperometric detection of neomycin
}

\author{
Yongsheng Ding ${ }^{\mathrm{a}, \mathrm{b}}$, Hong $\mathrm{Yu}^{\mathrm{a}}$, Shifen Mou ${ }^{\mathrm{a}, *}$ \\ ${ }^{a}$ Research Center for Eco-Environmental Sciences, Chinese Academy of Sciences, P.O. Box 2871, Beijing 100085, China \\ ${ }^{\mathrm{b}}$ Department of Chemical Biology, School of Pharmaceutical Sciences, Peking University Health Science Center, Beijing 100083, China
}

Available online 10 February 2004

\begin{abstract}
Determination of neomycin is important for quality control of the pharmaceutical preparation. A quadruple-potential waveform used for pulsed amperometric detection of neomycin was investigated. The waveform cleans the electrode by application of a potential more negative than the potential limit to avoid the formation of gold oxide during applying positive potential to clean gold electrode, thus decreasing the dissolution resulting recession of the gold working electrode within gold oxide formation/reduction cycles in the triple-potential waveform. Waveform parameters were optimized to maximize the signal-to-noise ratio $(\mathrm{S} / \mathrm{N})$. The detection limit of neomycin B is lower than $0.01 \mu \mathrm{g} / \mathrm{ml}$. The linearity of framycetin (plotted as peak area of neomycin B) ranges from 0.05 to $100 \mu \mathrm{g} / \mathrm{ml}$ with correlation coefficient 0.9998 . R.S.D. $(n=60)$ of the peak area of neomycin B is lower than $2 \%$. The quadruple-potential waveform shows low detection limits and long-term reproducibility. (C) 2004 Elsevier B.V. All rights reserved.
\end{abstract}

Keywords: Detection, LC; Waveforms; Pulsed amperometric detection; Neomycin; Antibiotics; Aminoglycosides; Glycosides

\section{Introduction}

Neomycin, which is used as the sulfate, is a widely-used broad spectrum water-soluble aminoglycoside antibiotic produced during fermentation of Streptomyces fradiae [1]. It inhibits the growth of Gram-negative and Gram-positive bacteria. It has a narrow therapeutic range, is potentially toxic like other aminoglycosides and may cause ototoxicity and nephrotoxicity. Neomycin is mainly composed of a mixture of neomycin B (Fig. 1) and its stereoisomer neomycin $C$ [2]. The antimicrobial potency of neomycin $C$ is lower than that of neomycin B. The difference in activity requires a limit and control of neomycin $\mathrm{C}$ in pharmaceutical preparation. The European Pharmacopoeia limits the amount of neomycin $\mathrm{C}$ to 3-15\% [3]. Neomycin with a content of less than $3 \%$ neomycin $\mathrm{C}$ is called framycetin.

The analysis of antibiotics is crucial to the proper administration of these drugs for human and animal consumption. These methods to analyze antibiotics are invaluable to the discovery, development, and formulation of antibiotic-based

\footnotetext{
* Corresponding author. Tel.: +86-1062849182; fax: +86-1062849239.

E-mail address: shifenm@mail.recees.ac.cn (S. Mou).
}

drugs and products. Traditionally, antibiotics have been analyzed by nonspecific bioassay, but the methods allow interferences from active metabolites, degradants, and other antibiotics. Since aminoglycosidic antibiotic detection limits by short-wavelength UV detection are poor, the derivatization is often used to improve the detection properties of aminoglycosides [4-6], but its procedures increase sample preparation and limit analytes applicability to reactive compounds.

The high sensitivity and selectivity of electrochemical detection are desired for antibiotic determination in complex matrices. DC amperometry is often accompanied with a daily ritual of disassembling the electrochemical cell and mechanically polishing the working electrode surface. Pulsed electrochemical detection (PED) with "on-line" cleaning was developed to maintain uniform and reproducible electrode activity at noble metal electrodes for polar aliphatic compounds [7]. The most widely utilized PED waveform is the three-step waveform. In the three-step waveform, the electrode potential is first stepped to the optimum value for detection of the electroactive species $\left(E_{\text {det }}\right)$. Following a delay time $\left(t_{\text {del }}\right)$, during which the current mainly from double-layer charging is permitted to decay to minimal value, the analytical signal is computed 


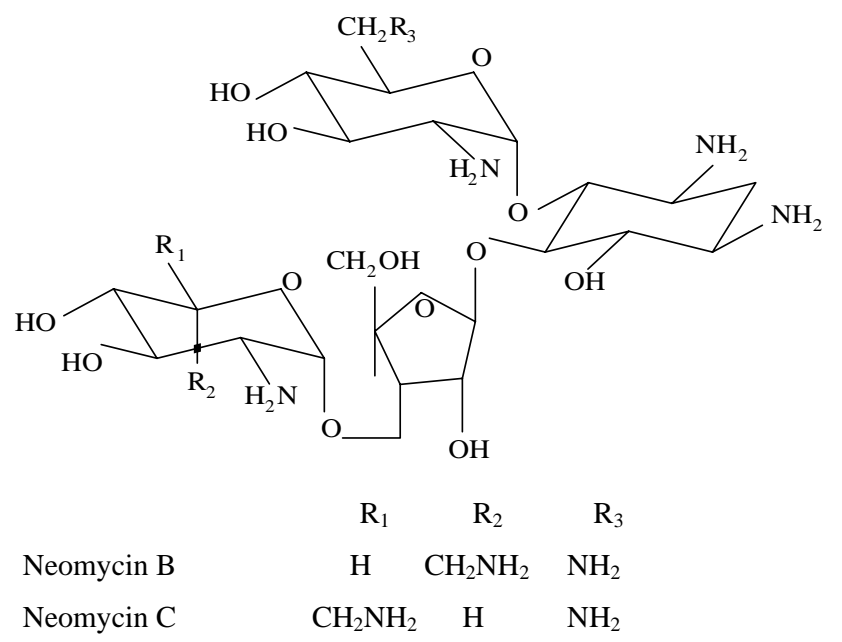

Fig. 1. The chemical structure of neomycin.

by integrating the faradaic current due to analyte oxidation for a specified time period $\left(t_{\text {int }}\right)$. The potential then is stepped to a more positive value $\left(E_{\mathrm{oxd}}\right)$ at which the electrode surface is oxidatively cleaned of any compounds adsorbed during the detection step. Finally, the potential is stepped to a negative value $\left(E_{\text {red }}\right)$ to reduce the oxide layer formed at $E_{\text {oxd }}$, thereby regenerating the electrode activity so that the cycle may be repeated.

Aminoglycoside antibiotics were first determined by pulsed amperometric detection at a platinum electrode by Polta and Johnson [8]. Statler extended this work by anion-exchange chromatography followed by pulsed amperometric detection at $\mathrm{Au}$ electrode under alkaline conditions [9]. Neomycin was determined by anion-exchange chromatography with pulsed electrochemical detection [10]. Adams et al. applied a column packed with a poly(styrenedivinylbenzene) co-polymer and pulsed amperometric detection to determine neomycin [11]. High-performance liquid chromatography with electrochemical detection was chosen by the European Pharmacopoeia to determine neomycin sulfate [3]. Most of above research work focused on the triple-potential waveform by using the electrochemical detector PED-1 (Dionex) with larger amperometric cell (Au electrode $3 \mathrm{~mm}$ i.d., cell volume $1 \mu \mathrm{l}$ ). The parameters in these old waveforms are not suitable to apply in ED50 (Dionex) with smaller amperometric cell (Au electrode $1 \mathrm{~mm}$ i.d., cell volume $0.2 \mu \mathrm{l}$ ) that is now commonly used. Jensen and Johnson [12] and Rocklin et al. [13] successfully introduced high frequency waveforms for detection of carbohydrates by using smaller amperometric cell, respectively. Compared to the triple-potential waveform, the quadruplepotential waveform showed long-term reproducibility. In this paper, we have applied a quadruple-potential waveform for pulsed amperomeric detection of neomycin. The results of experiment show applicability of the method due to increased reproducibility of the quadruple-potential waveform.

\section{Experimental}

\subsection{Chemicals}

Framycetin sulphate CRS was obtained from Long Match Pharmaceutical Co., Sichuan, China. Sodium hydroxide solution was prepared by dilution of a $50 \%(\mathrm{w} / \mathrm{w})$ stock solution (self-made, solid sodium hydroxide were purchased from Beijing Chemical Co.). Trifluoroacetic acid (99\%) was purchased from Janssen Chimica (Geel, Belgium). Deionized water used for preparation of all chromatographic solutions was purified by a compact ultrapure water system (Barnstead, IA, USA).

\subsection{Apparatus}

A Dionex BioLC system consists of a GS50 gradient pump, an ED50 electrochemical detector with a thin-layer type amperometric cell, and an AS50 autosampler with $25 \mu \mathrm{l}$ injection loop. The work electrode is made from a $1 \mathrm{~mm}$-diameter gold rod, force-fit into a Kel-F plastic block. The counter electrode is the titanium cell body across the $25-\mu \mathrm{m}$ thin-layer channel from the working electrode. A $\mathrm{pH}-\mathrm{Ag} / \mathrm{AgCl}$ reference electrode is downstream from the thin-layer channel. All chromatography data acquisition and instrument control were performed using Dionex PeakNet 6.0 software.

\subsection{Chromatography}

A column (Hypersil BDS $\mathrm{C}_{18}, 5 \mu \mathrm{m}, 250 \times 4.6 \mathrm{~mm}$, Elite Analytical Instruments, Dalian, China), packed with base-deactivated octadecylsilyl silica gel, was used to separate neomycin. The mobile phase: mix $20.0 \mathrm{ml}$ of trifluoroacetic acid, $6 \mathrm{ml}$ of carbonate-free $50 \%(\mathrm{w} / \mathrm{w})$ sodium hydroxide solution, and $500 \mathrm{ml}$ of water, allow to equilibrate, dilute to $1000 \mathrm{ml}$ with water and degas. Flow rate was $0.7 \mathrm{ml} / \mathrm{min}$. Through a mixing-tee, $0.5 \mathrm{M} \mathrm{NaOH}$ was added post-column from a Nitrogen pressurized reservoir $(22-23 \mathrm{psi}, 1 \mathrm{psi}=6894.76 \mathrm{~Pa})$ and mixed in a packed reaction coil $(1.2 \mathrm{~m}, 500 \mu \mathrm{l})$ which was linked to the electrochemical cell. The post-column addition of the base must be pulse-free with a flow rate of $0.3 \mathrm{ml} / \mathrm{min}$. Although the flow rate is not critical, it should be reproducible between runs. The potential and time for detector are shown in Table 1 . The injection of $10 \mu l$ sample was performed by an AS50 autosampler.

\section{Results and discussion}

\subsection{Waveform optimization}

\subsubsection{Detection potential (E1)}

Each of the four potentials shown in Table 1 performs a different function. The first potential (E1) is the detection 
Table 1

Pulsed amperometric detection waveform

\begin{tabular}{lccl}
\hline & Potential $(\mathrm{V})$ & Time $(\mathrm{ms})$ & Integrated \\
\hline E1 & 0.0 & 0 & \\
& 0.0 & 300 & Begin \\
& 0.0 & 500 & End \\
E2 & -1.6 & 510 & \\
& -1.6 & 520 & \\
E3 & 0.6 & 530 & \\
E4 & -0.15 & 540 & \\
& -0.15 & 600 & \\
\hline
\end{tabular}

potential at which the current from neomycin oxidation is integrated. Using pulsed amperometric detection, graph (Fig. 2) of the signal-to-noise ratio as a function of detection potential shows that the maximum response for neomycin is from -0.1 to $+0.15 \mathrm{~V}$. The potential $0.0 \mathrm{~V}$ was selected as $\mathrm{E} 1$ because the noise at $0.0 \mathrm{~V}$ is the lowest (the data not shown).

The response is directly proportional to the integration period and a long delay time decreases noise, but the total waveform period used is limited. If the total waveform period is longer than $0.6 \mathrm{~s}$ in the amperometric cell (Au electrode $1 \mathrm{~mm}$ i.d., cell volume $0.2 \mu \mathrm{l}$ ), the chromatogram will be not "smooth" like as normal (Fig. 3). It may be caused by the limit of the instrument. In this test, we distributed the period for detection potential $0.5 \mathrm{~s}$. It was shown that the effect of integration time on the $\mathrm{S} / \mathrm{N}$ of analyte in Fig. 4. The integration time/delay time $(200 / 300 \mathrm{~ms})$ was selected in the four-potential waveform.

\subsubsection{Cleaning potential (E2)}

With the triple-potential waveform, the working electrode is cleaned by removal of gold from the electrode following each repetition of the positive potential. The cleaning function is accomplished in the quadruple-potential waveform at high negative instead of high positive potential. A plot of the signal-to-noise ratio for neomycin $\mathrm{B}$ as a function of the

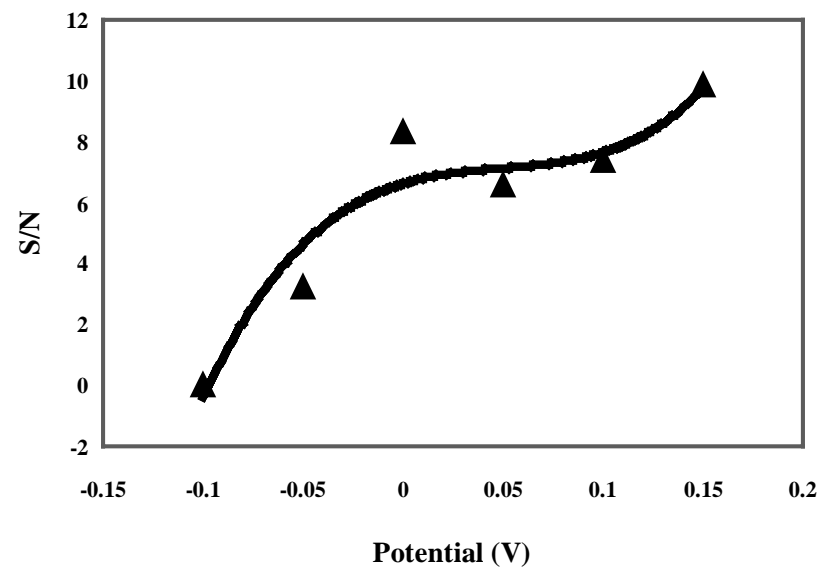

Fig. 2. Effect of different detection potential on the $\mathrm{S} / \mathrm{N}$ of neomycin $\mathrm{B}$.

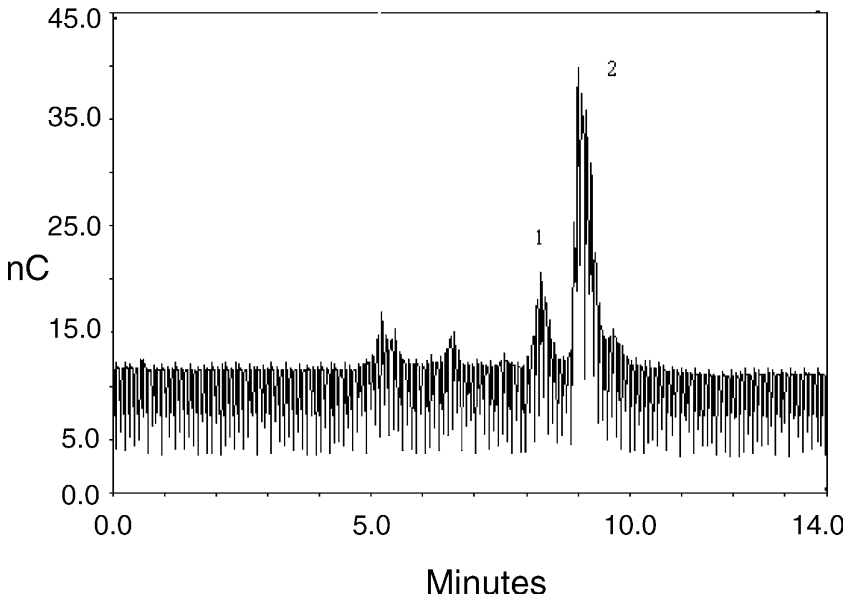

Fig. 3. The chromatogram of a framycetin sulphate $(5 \mu \mathrm{g} / \mathrm{ml})$ under the period time of waveform beyond $600 \mathrm{~ms}$. 1: Neomycin C; 2 . neomycin B. Chromatographic conditions: column, Hypersil BDS $\mathrm{C}_{18}$, $5 \mu \mathrm{m}, 250 \times 4.6 \mathrm{~mm}$; mobile phase: mixing $20.0 \mathrm{ml}$ of trifluoroacetic acid, $6 \mathrm{ml}$ of carbonate-free $50 \%(\mathrm{w} / \mathrm{w})$ sodium hydroxide solution, and $974 \mathrm{ml}$ of water; flow rate, $0.7 \mathrm{ml} / \mathrm{min}$, post column reagent: $0.5 \mathrm{M} \mathrm{NaOH}$ at $0.3 \mathrm{ml} / \mathrm{min}$. Detection waveform (WF) is given in Table 1 , but the end time of WF is $690 \mathrm{~ms}$.

negative cleaning potential is shown in Fig. 5. The result shows that the value of $\mathrm{S} / \mathrm{N}$ arrives maximum at approximately -1.7 to $-1.6 \mathrm{~V}$.

The mechanism of cleaning at negative potential could be displacement of adsorbed molecules on the electrode surface by hydrogen atoms produced from the reduction of water. Oxidation of these adsorbed hydrogen atoms at the detection potential is the likely cause of noise observed as the negative cleaning time is increased or the potential is made more negative (the data not shown). Improved electrode cleaning can be accomplished by increasing the time during which the negative cleaning potential is applied, but at the cost of increasing noise. The recommended $10 \mathrm{~ms}$ hold at the negative potential was selected to accomplish effective cleaning without excessive noise.

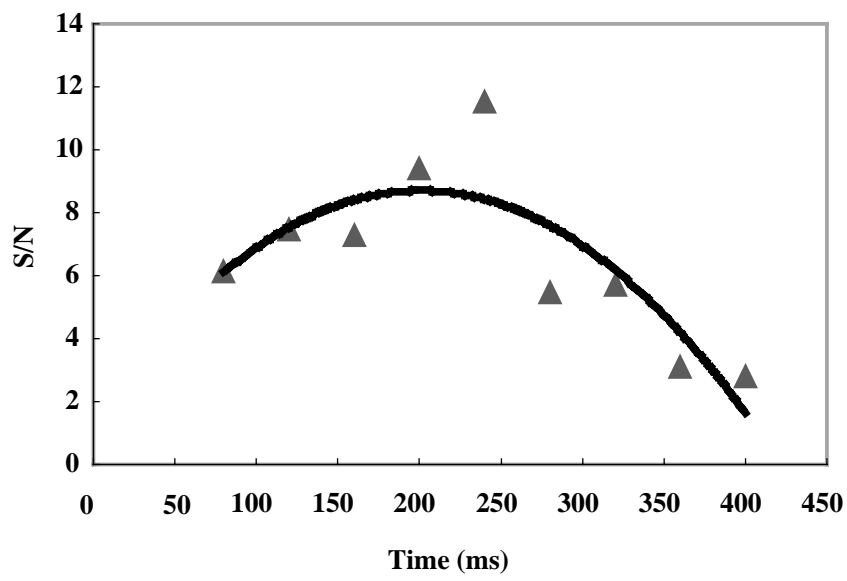

Fig. 4. Effect of different integration/delay time on the $\mathrm{S} / \mathrm{N}$ of neomycin B 


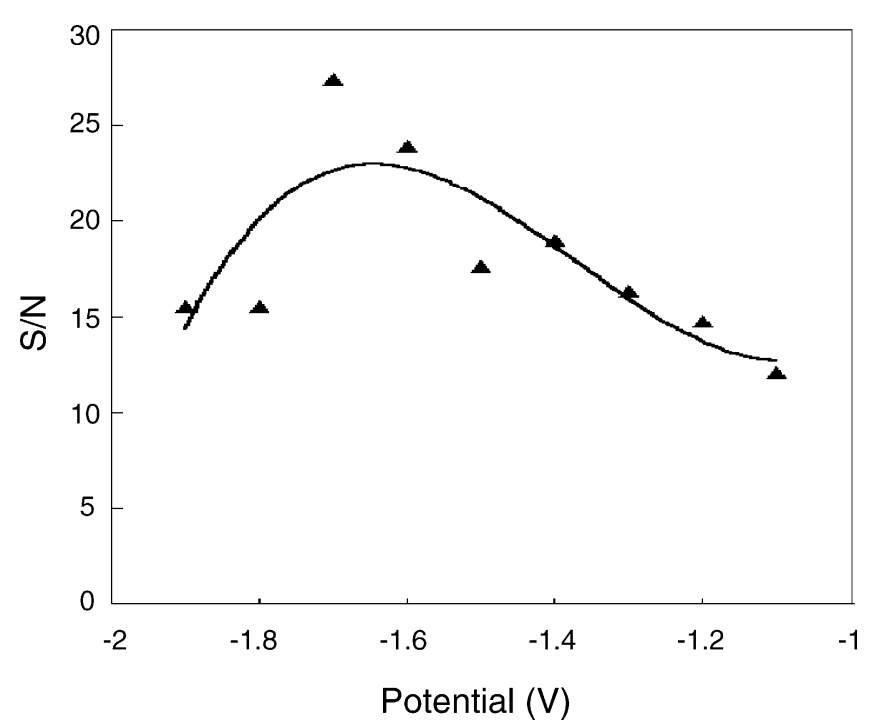

Fig. 5. Effect of different cleaning potential on the $\mathrm{S} / \mathrm{N}$ of neomycin $\mathrm{B}$.

\subsubsection{Activation potentials (E3)}

The purpose of the third potential is to maintain an active electrode. Aminoglycoside oxidation on the Au electrode has been verified to be surface-catalyzed reaction. Catalytic sites on the gold electrode are thought to be low-coordination gold atoms such as those at grain boundaries. It is believed that these catalytic sites are created during forming and then reducing surface oxide. The activation potential was ramp up then down without holding to avoid electrode recession. When the activation potential from +0.1 to $+0.9 \mathrm{~V}$ were tested, the responses of analyte showed no obvious change from the chromatograms at different potential. In order to maintain electrode active, the activation potential was selected as $+0.6 \mathrm{~V}$.

\subsubsection{Oxide reduction potential (E4)}

The fourth potential has two purposes. First, is to reduce oxide formed at the positive activation potential. Second, is to adsorb the analytes for enhancing detection sensitivity. This gold oxide reduction potential was chosen to be negative, but not so negative as to reduce dissolved oxygen. Fig. 6 shows the effect of reduction potential on the $\mathrm{S} / \mathrm{N}$ of the analyte. When the reduction potential arrives at $-0.15 \mathrm{~V}$, the $\mathrm{S} / \mathrm{N}$ of the analyte is the largest. Since the reduction of gold oxide is relatively fast, the time spent at this potential is not critical. The period used was chosen to round out the waveform to $0.6 \mathrm{~s}$.

\subsection{Effect of $p H$}

The potentials chosen for the quadruple-potential waveform were selected from experiments performed under the condition of $\mathrm{pH}>12$. However, the optimum potentials display approximately Nernstian behavior with changing $\mathrm{pH}$ as a result of the $\mathrm{pH}$-dependent shift of gold oxide forma-

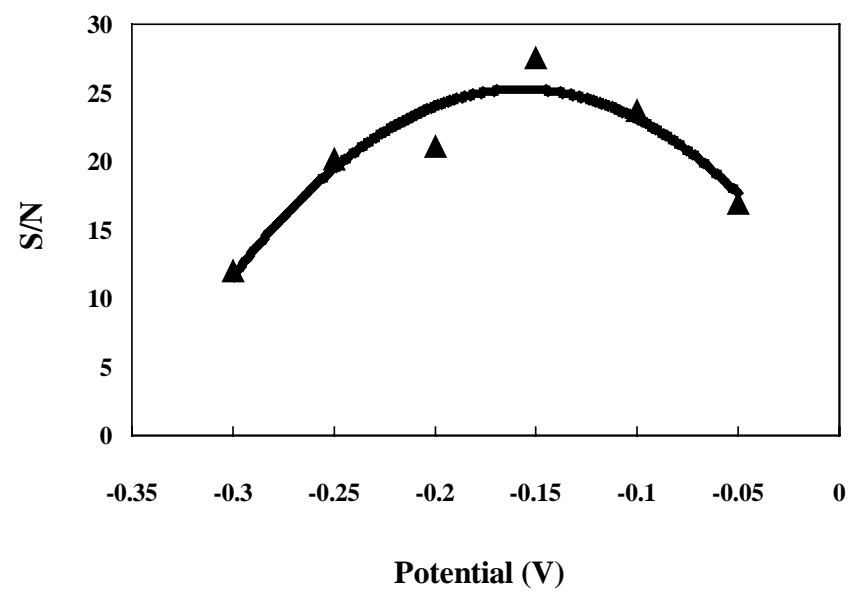

Fig. 6. Effect of different reduction potential on the $\mathrm{S} / \mathrm{N}$ of neomycin B.

tion and reduction potentials. If the $\mathrm{pH}$ of mobile phase is shifted more than one unit, the detection potential and oxide reduction potential are the only potential which need to be shifted. The cleaning potential and the oxide formation potential show little potential dependence, so there is no need to shift these potentials as $\mathrm{pH}$ is changed. Generally, the constant $\mathrm{pH}$ is helpful to the reproducibility of response.

\subsection{The method evaluation}

With using four-potential waveform, a typical chromatogram of neomycin for examining related substances is shown in Fig. 7. The optimized waveform was also evaluated by detection limit, linearity, and reproducibility. The detection limit of neomycin B (three time noise level) is lower than $0.01 \mu \mathrm{g} / \mathrm{ml}$ (Fig. 8). The linearity of framycetin, plotted as peak area of neomycin B versus the concentration of sample injected, ranges from 0.05 to $100 \mu \mathrm{g} / \mathrm{ml}(r=$ 0.9998). The reproducibility was performed by repeatedly

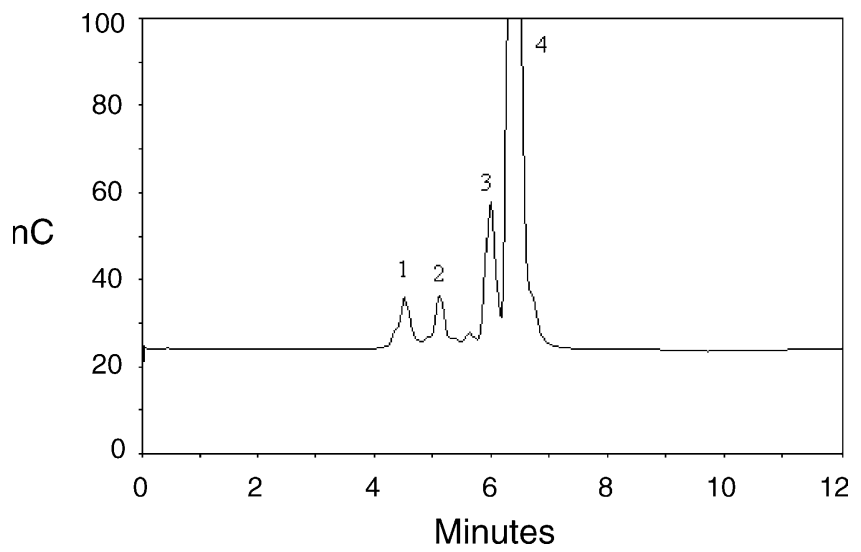

Fig. 7. The chromatogram of framycetin sulfate $(0.5 \mathrm{mg} / \mathrm{ml}) .1,2$ : Unknown impurities; 3: neomycin C; 4: neomycin B. Chromatographic conditions are provided in Fig. 3; detection waveform is given in Table 1. 


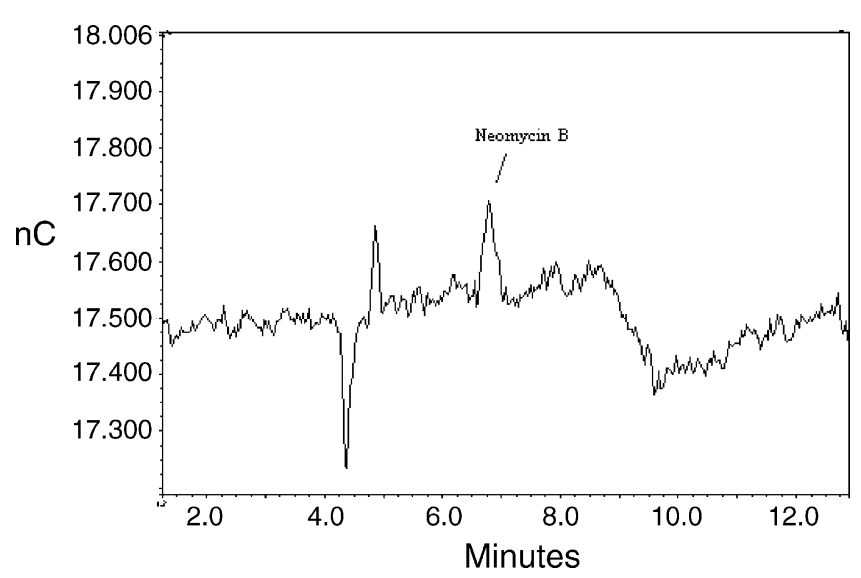

Fig. 8. The chromatogram of limit detection. The concentration of framycetin sulfate is $0.01 \mu \mathrm{g} / \mathrm{ml}$; chromatographic conditions are provided in Fig. 3; detection waveform is given in Table 1.

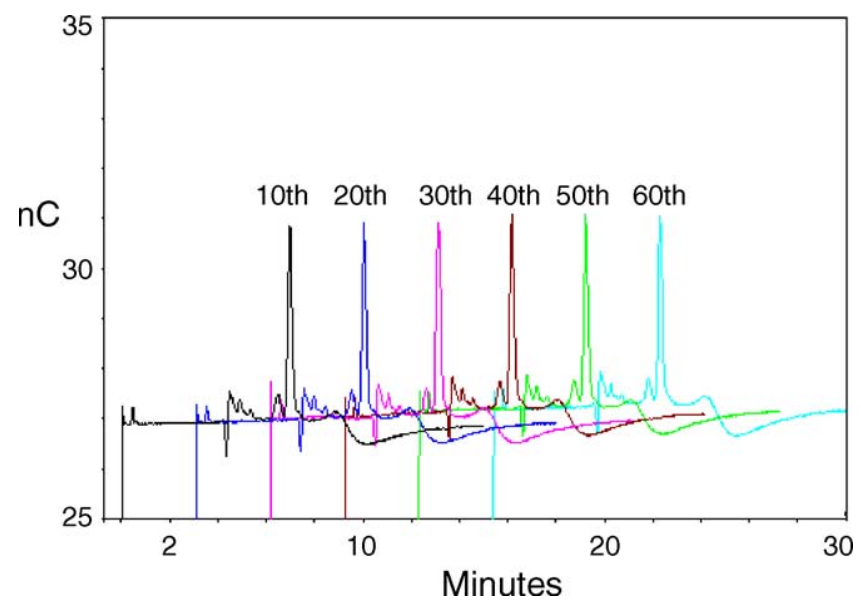

Fig. 9. The chromatogram of framycetin sulfate $(5 \mu \mathrm{g} / \mathrm{ml})$ at the different injection times. Chromatographic conditions are provided in Fig. 3; detection waveform is given in Table 1.

running samples for 3 days. The responses of analyte showed little change and the surface of Au electrode also retained clean. The R.S.D. $(n=60)$ of peak area of neomycin $\mathrm{B}$ was lower than $2 \%$. The chromatograms of neomycin sulfate $(5 \mu \mathrm{g} / \mathrm{ml})$ at the different injection times are shown in Fig. 9.

\section{Conclusion}

The quadruple-potential waveform greatly improves long-term reproducibility for pulsed amperometric detection of neomycin. With high frequency of sampling, the quadruple-potential waveform can be applied in the small amperometric cell (ED50, Dionex) for detection of neomycin. In addition to the advantage of improved reproducibility on the chromatography, minimizing electrode recession also minimizes the response differences between working electrodes. The quadruple-potential waveform is suitable to be used in quality control and in other situations when the results from one chromatograph must be compared to results on another, or where changes in peak area over time must be monitored.

\section{References}

[1] S.A. Waksman, H.A. Lechevalier, Science 109 (1949) 305.

[2] J.D. Dutcher, N. Hosansky, M. Donin, O. Wintersteiner, J. Am. Chem. Soc. 73 (1951) 1384.

[3] European Pharmacopoeia 4.4, fourth ed., Maisonneuve, Sainte Ruffine, France.

[4] C. Feng, S. Lin, H. Wu, S. Chen, J. Chromatogr. B 780 (2002) 349.

[5] E. Kaale, S. Leonard, A. Van Schepdael, E. Roets, J. Hoogmartens, J. Chromatogr. A 895 (2000) 67.

[6] E. Kaale, A. Van Schepdael, E. Roets, J. Hoogmartens, J. Chromatogr. A 924 (2001) 451.

[7] D.C. Johnson, Nature 321 (1986) 451

[8] J.A. Polta, D.C. Johnson, J. Chromatogr. 324 (1985) 407.

[9] J.A. Statler, J. Chromatogr. 527 (1990) 244.

[10] Application Note 66 R, Neomycin in Topical Lotions, Dionex, Sunnyvale, CA, 1991.

[11] E. Adams, R. Schepers, E. Roets, J. Hoogmartens, J. Chromatogr. A 741 (1996) 233.

[12] M.B. Jensen, D.C. Johnson, Anal. Chem. 69 (1997) 1776.

[13] R.D. Rocklin, A.P. Clarke, M. Weitzhandler, Anal. Chem. 70 (1998) 1496. 